\title{
Study on Car Seat Ease-of-Use Rating Based on Safety Factors in China
}

\author{
Liu Kai ${ }^{1,2, a}$, Qian Yubin ${ }^{2}$, Xiao Lingyun ${ }^{1, b, \star}$, Dong Honglei ${ }^{1}$, Hu Wenhao ${ }^{1}$, \\ Wang Yan $^{1}$, Zhang Jinhuan ${ }^{3}$ \\ ${ }^{1}$ AQSIQ Defective Production Administrative Center(DPAC), Beijing 100101, China; \\ ${ }^{2}$ Shanghai University of Engineering Science, Shanghai 201620, China; \\ ${ }^{3}$ Tsinghua University, Beijing 100084, China. \\ a1065790643@qq.com, bxiaoly@dpac.gov.cn
}

Key Words: Car Seat; Misuse; Ease-of-Use Rating; Children's Injury; Traffic Accident

\begin{abstract}
Children are one of the most vulnerable groups in traffic accidents. Correct use of car seat can effectively reduce the children's injury and fatality in traffic accidents. First of all, this paper analyzes the trend of the children's injury and fatality caused by traffic accidents in China, and introduces the survey on misuse of car seats in several large cities in China. Then, this paper analyzes the children's injury by car seat misuse tests, and proposes the study method and framework about the Ease-of-Use Rating of car seat based on the different safety factors which are related to different misuse circumstances. Moreover, through the future analysis and verification, such as ease-of-use tests, misuse tests and hierarchical analysis, the China Car Seat Ease-of-Use Rating is proposed. This study will promote the industry to further emphasize the ease-of-use design of car seat, and also further improve the use rate of car seat in China.
\end{abstract}

\section{Introduction}

Traffic accident is a major cause of children's injury and fatality. According to the report of the World Health Organization (WHO) and the U. N. Children's Fund, road traffic accidents lead to 260,000 children's fatality and about 10 million children's injuries every year [1]. In Europe, about 1,200 children under 16 years die from road traffic accidents every year, $40 \%$ of them are in cars [2]. Road traffic accident ranks the top among the five major hazards (road traffic accidents, drowning, burns, fall and poisoning) for children's injury and fatality [3].

Along with the widely use of the car seat, children's traffic safety attracts growing attention. But children's safety cannot be completely ensured without the proper use of the car seat. Related studies have shown that $[4,5]$ proper use of car seat can reduce the fatality rate of infants by $71 \%$ and of children aged 1-4 by 54\%. Several cities or provinces have successively made relevant regulations on compulsory use of the car seat [6] in China, such as, Shanghai [7], Hangzhou [8], Shandong [9]. The regulations forbid children under 12 years from sitting in the front passenger seat, and require children under 4 years to sit in car seat when riding in the car. However, is the car seat really safe? Due to people's limited understanding of car seat, the misuse of car seat is common. So some countries have researched and made the procedures for ease-of-use rating of car seat to reduce the misuse. Ease-of-Use 5-Star Rating [10] of the National Highway Traffic Safety Administration (NHTSA) is a typical example. It mainly includes Evaluation of Labels, Evaluation of Instructions, Securing the Child and Vehicle Installation Features. 
Based on the survey of the children's injuries in traffic accidents and the use rate of the car seat, this paper carries out study on the car seat ease-of-use rating and forms the ease-of-use rating procedures which is complied with the status quo of the car seat market in china. This study will reduce the misuse of car seat, and the manufactures will design more car seats which are high rated of ease of use.

\section{Survey on Children Traffic Accidents and the Use of Car Seat in China}

\subsection{The statistics of the Children Traffic Accident in China}

The children traffic accident refers to the traffic accidents involved the children under 14 years [3]. From 2001 to 2014, the children's fatality caused by traffic accidents in china was declining as shown in Fig. 1 [3]. Although the number of the children's fatality keeps declining year by year, but the total number is still large. Traffic accident is still one of the primary cause for children's injury and fatality in China.

\subsection{The In-depth Investigation on Children Traffic Accidents}

From 2011 to 2016, the database [11] of the National Automobile Accident In-Depth Investigation System (NAIS) has gathered 127 accident cases which involved children occupants without using the car seat, including 24 fatality, 47 injured and 56 uninjured. Among them, the distribution of the injury and fatality of the front/rear-seated children occupants is shown in Fig. 2.

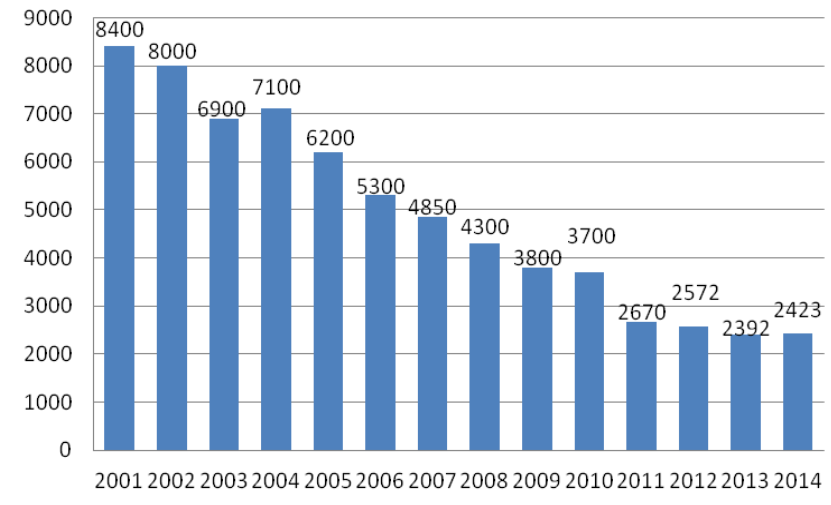

Fig. 1 The Number of Children's Fatality Caused by Traffic Accident

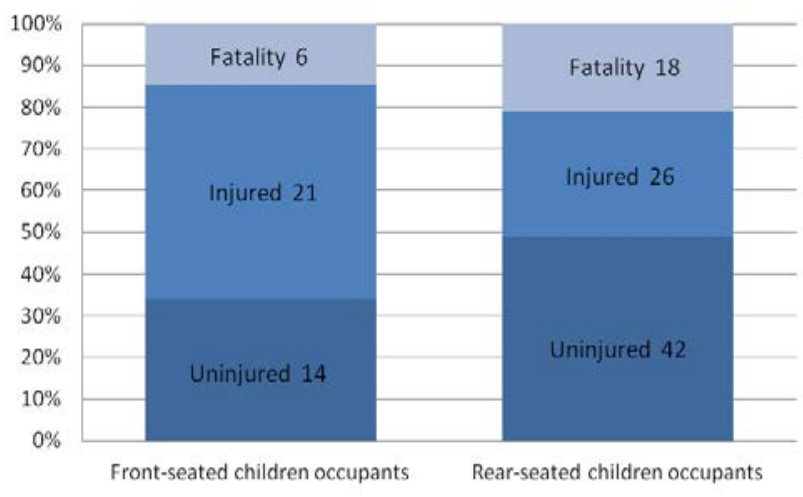

Fig. 2 Distribution of Injuries and Fatalities of Front/Rear-seated Children Occupants

As shown above, the injury and fatality of the front-seated children occupants reaches $65.9 \%$, and the injury and fatality of the rear-seated children occupants reaches $51.2 \%$. The data shows that the front-seated children occupants have a higher possibility to cause the serious injury and fatality than the rear-seated children occupants. The data also show that the injury and fatality is still serious and high without using the car seat.

\subsection{Survey on the Use of Car Seat in big Cities in China}

In order to learn the use rate of the car seat in big cities, a survey of 4,900 children's parents has been conducted in 5 big cities in China in 2015, including Beijing, Shanghai, Guangzhou, Chongqing and Jinan, and 4,375 valid questionnaires have been collected. The result (Fig. 3) shows that the use rate of car seat only reaches $16 \%$. 


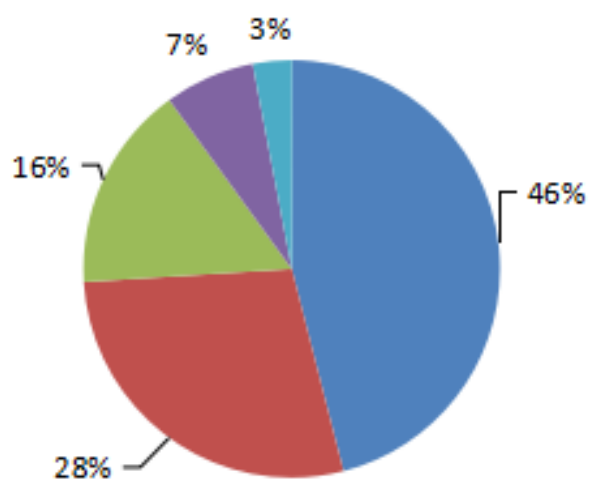

Fasten SB

Adult Supervision

Use car seat

No protection

Others

Fig. 3 The use rate of car seat in 5 cities in China

The questionnaire involves 5 common misuse modes of car seat $[12,13,14,15]$ : wrong seat installation position, slack seat belt (SB), slack harness belt (HB), twisted SB and twisted HB. Through the survey, 6.2\% parents install the car seat on the front passenger seat. The other 4 misuse modes are shown in Fig. 4. The misuse of Slack HB is more often than that of slack SB. The rate of the full check of the 4 misuse modes is quite low, and the misuse could be very often.

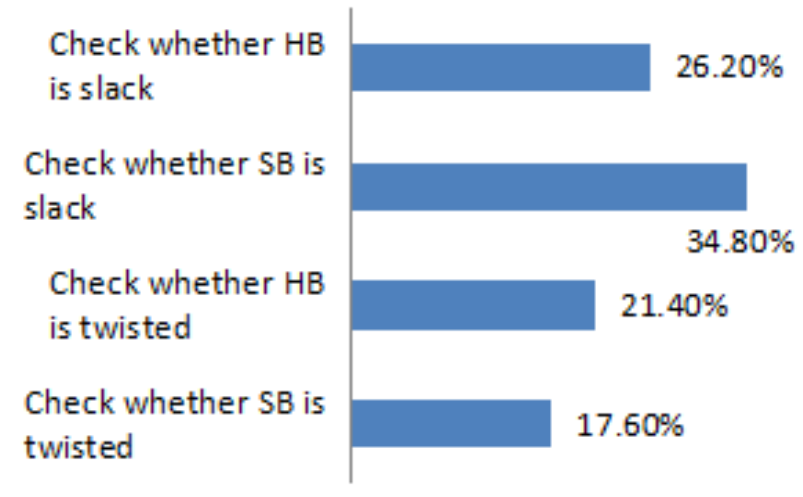

(a) The other 4 misuse modes

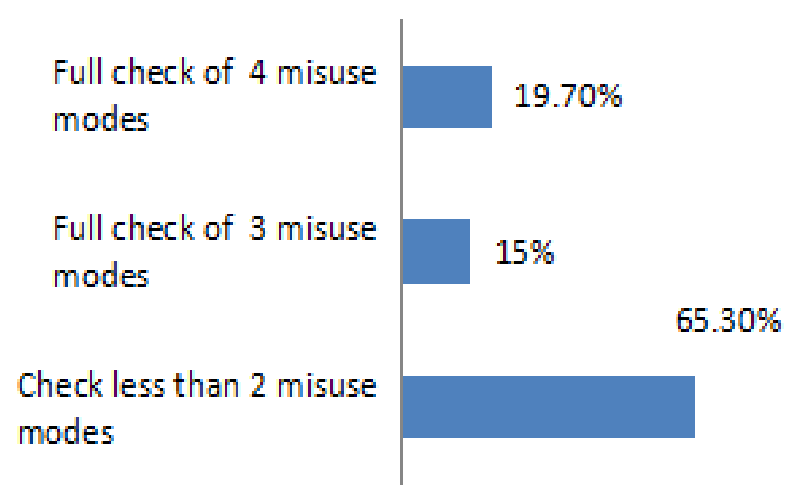

(b) The check rate of the 4 misuse modes

Fig. 4 Survey statistics of the Misuse Modes of Car Seat

\section{The Study Method of the Car Seat Ease-of-Use Rating Procedure}

Firstly, to purchase the sample car seats for compliance test [16] based on the market survey, and analyze the domestic and foreign misuse modes of the car seat, then to conduct sled tests for common misuse modes, and explore the influences of different misuse modes on children's traffic safety, and divide the risk grades of the different misuse modes. Secondly, to analyze the reasons of the misuse and the relationship between ease-of-use and misuse mode, and propose the ease-of-use indicators which conform to the product characteristics and market status quo of the car seat in China with reference to the car seat ease-of-use rating of NHTSA, then to adopt hierarchical analysis process to reasonably assign the weight of indicators according to the relationship between ease-of-use and misuse. At last, to further verify the rating indicators and their weights according to the ease-of-use tests and the rating results to make the procedure more practical and reasonable. The study method is shown in Fig. 5. 


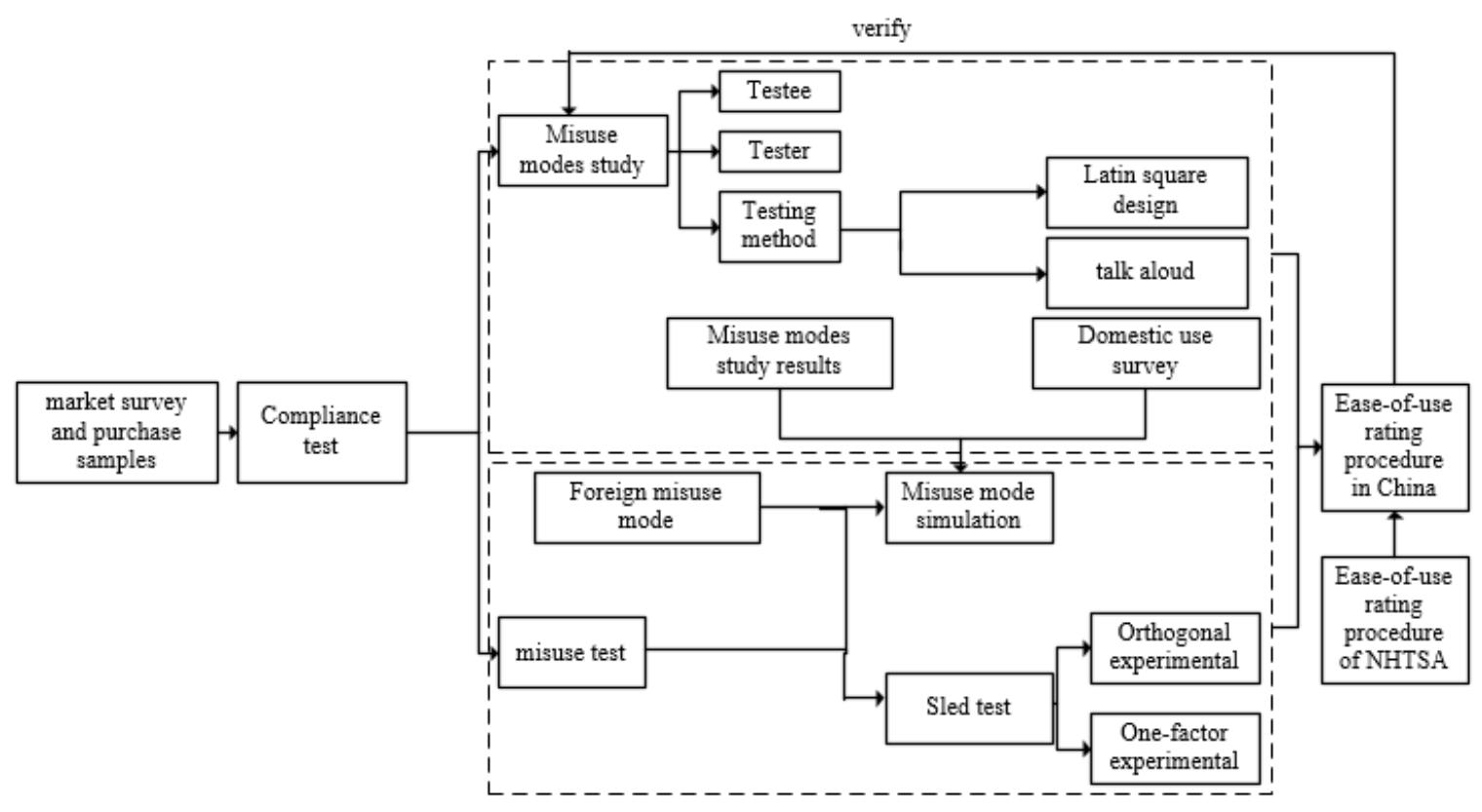

Fig. 5 Study Method for Ease-of-Use Rating in China

\section{Design of Car Seat Ease-of-use Rating Procedure in China}

\subsection{Study on the Misuse Modes of Car Seats}

Misuse modes study refers to observing the behavior of tester during installation of car seat to study the relationship between ease-of-use and misuse modes, and provide the basis for establishment of the ease-of-use indicators. We have conducted 144 tests with 12 volunteers. The result of the misuse modes is shown in Table 1.

Table 1 Result of Misuse Modes by volunteer tests

\begin{tabular}{lcrc}
\hline No. & Misuse modes & Misuse rate & Misuse degree \\
\hline 1 & Slack SB & $47.4 \%$ & $46 \mathrm{~mm}$ \\
2 & Inappropriate shoulder & $47.4 \%$ & -- \\
3 & belt height & $43.6 \%$ & $42 \mathrm{~mm}$ \\
4 & Slack HB & $41.0 \%$ & 1.34 pieces \\
5 & Twisted SB & $34.6 \%$ & 1.22 pieces \\
6 & Twisted shoulder belt & $16.7 \%$ & -- \\
7 & Wrong threading & $2.6 \%$ & -- \\
\hline
\end{tabular}

\subsection{The Study on the Car Seat Misuse Tests}

We conduct car seat misuse tests through sled impact tests. Firstly, we choose Twisted SB, Twisted HB, Slack HB and Slack SB to do orthogonal tests, and then conduct single-factor tests in 5 kinds of misuse modes, including no tensioning of buckle of HB, wrong adjustment to seat angle, wrong threading of seat safety belt, wrong children shoulder belt height and shoulder belt under the children armpit.

After Misuse test, the misuse testing results have been summarized in Table 2, and the injury risk grades of the different misuse modes have been analyzed and listed in Table 2 [17]. The test results and analysis results could provide a scientific and objective basis for indicator weight assignment of ease-of-use rating system. 
Table 2 The Injury Risk Grades of Car Seat Misuse Modes

\begin{tabular}{lllcc}
\hline $\begin{array}{l}\text { Serial } \\
\text { Number }\end{array}$ & \multicolumn{1}{c}{ Misuse Modes } & $\begin{array}{l}\text { Head } \\
\text { HIC15 }\end{array}$ & $\begin{array}{l}\text { X Displacement } \\
\text { of Head }\end{array}$ & $\begin{array}{c}\text { Injury Risk } \\
\text { Grades }\end{array}$ \\
\hline 1 & No tensioning of buckle of HB & -- & -- & 10 \\
2 & Shoulder belt under the children armpit & $\mathbf{1 3 2 6}$ & 732 & 9 \\
3 & Age of children fails to conform to weight & -- & -- & 8 \\
4 & Wrong children shoulder belt height & $\mathbf{1 1 4 1}$ & 591 & 7 \\
5 & Wrong threading of seat safety belt & $\mathbf{9 6 3}$ & 577 & 6 \\
6 & Slack SB & 348 & $\mathbf{6 5 0}$ & 5 \\
7 & Wrong adjustment to seat angle & 483 & $\mathbf{5 9 1}$ & 4 \\
8 & Slack HB & -- & $\mathbf{P}<\mathbf{0 . 0 1}$ & 3 \\
9 & Twisted HB & -- & $\mathbf{0 . 0 1}<\mathbf{P}<\mathbf{0 . 0 5}$ & 2 \\
10 & Twisted SB & -- & $\mathbf{P}>\mathbf{0 . 0 5}$ & 1 \\
\hline
\end{tabular}

\subsection{Rating Framework of the Car Seat Ease-of-use}

Based on the misuse modes study, misuse tests and foreign ease-of-use procedures, this paper has established the overall framework for ease-of-use rating of car seat as shown in Fig. 6, which mainly includes "Three Layers". The procedure of the car seat ease-of-use rating includes four aspects, such as labels rating, operating instructions rating, children protection rating and car seat installation rating.

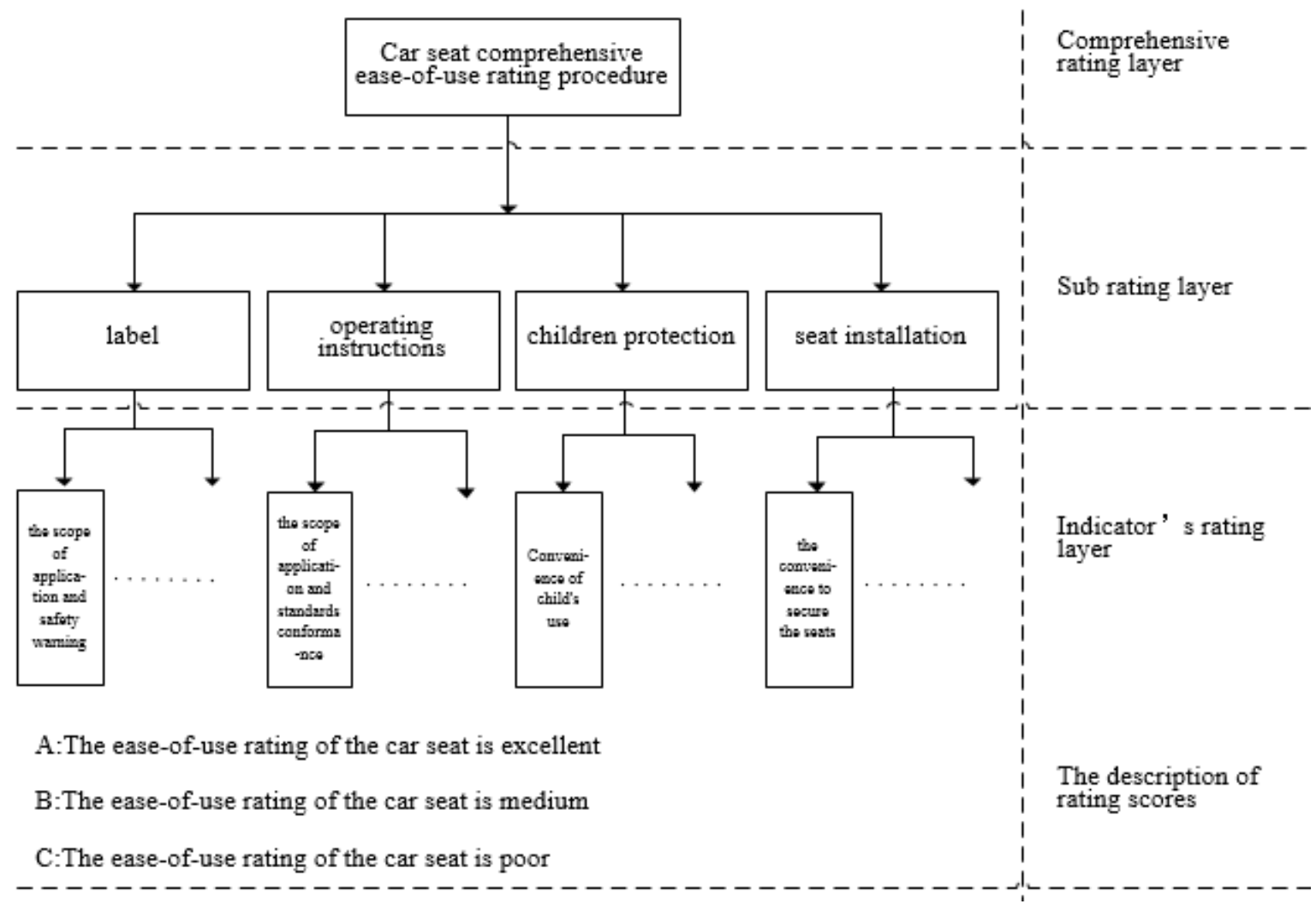

Fig. 6 Rating Framework of Car Seat Ease-of-Use 


\subsection{Establishment of the Car Seat Ease-of-use Rating Indicator System}

\subsubsection{Assignment of the Ease-of-use Rating Indicators and their Weight}

Based on the results of the misuse modes study and the misuse tests and the foreign ease-of-use rating procedure, this paper proposes the rating indicator system which including four aspects, such as "label”, "operating instructions", “children protection" and "car seat installation". The "label” includes 8 indicators, the "operating instructions" includes 9 indicators, the "children protection" includes 10 indicators and the "car seat installation" includes 5 indicators. Considering the car seat misuse risk grades, the different children groups should focus on different indicators for the "children protection" aspect. For example, for children occupants from Group 0, 0+ and I, the misuse of buckles and shoulder belts has larger influence on the safety of children occupants, therefore, the operation convenience of buckles and shoulder belts on car seat harness should be assigned higher weight. For children occupants from Group II and III, the misuse of harness has larger influence on the safety of children occupants, therefore, the operation convenience and restraint rationality of the seat belt should be assigned higher weight.

With reference to the ease-of-use rating procedure of NHTSA, the weight of the four aspects has been assigned in this paper by the hierarchy analytic process, the weight of "label", "operating instructions”, “children protection” and “car seat installation” are respectively 1, 2, 4 and 4.

\subsubsection{Amendment of the Rating Indicators and their Weight}

During the study of the misuse modes and misuse tests, we realized that the operating instruction of most of the sample car seats is designed to store on the car seat body, but it is not convenient to pick out and read, and the operating instruction is very easy to lose during using the car seat. Besides, the label with reasonable pasted position and clear specifications can provide greater help during seat installation.

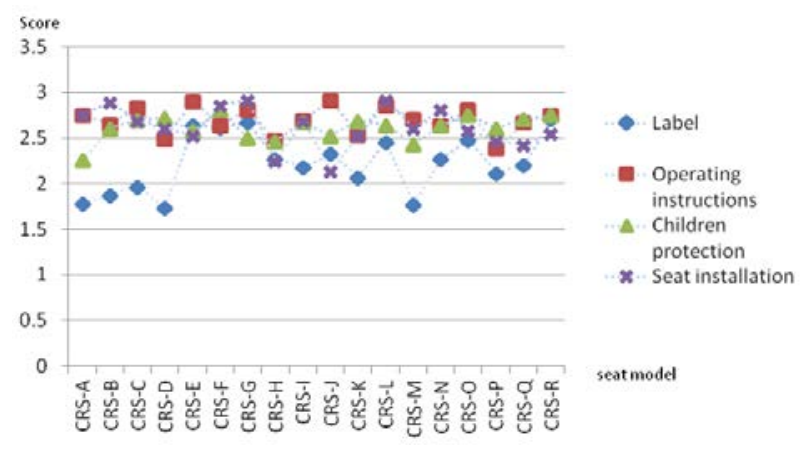

Fig. 7 The rating results of 18 car seats

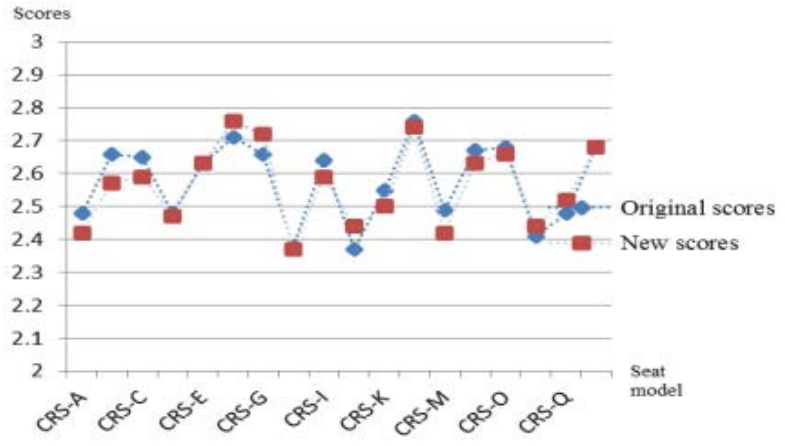

Fig. 8 Comparison of the rating results between the original weight and new one

To verify and amend the rating indicators and their weight, we conducted the ease-of-use tests with 18 car seats following the rating procedure proposed above, the rating results of 4 aspects are shown in Fig.7. The rating score of "label" aspect is obviously lower than that of the other three aspects, which indicates that the label of most car seats in China have flaws in the ease-of-use design, and remind us that the car seat ease-of-use design should pay more attention to the label design. To solve above problems, the following improvements have been proposed, such as, to increase the weight of "label" from 1 to 2, and to reduce the weight of "children protection" and "car seat installation" from 4 to 3.5. The details of the amendment are shown in Table 3. The comparison of the rating results of between the original weight and the new one are shown in Fig.8. 
Table 3 Weight Assignment Comparison

\begin{tabular}{ccccc}
\hline & Labels & Operating instructions & Children protection & Seat installation \\
\hline The Original weight & $1(9.09 \%)$ & $2(18.18 \%)$ & $4(36.36 \%)$ & $4(36.36 \%)$ \\
The New weight & $2(18.18 \%)$ & $2(18.18 \%)$ & $3.5(31.82 \%)$ & $3.5(31.82 \%)$ \\
\hline
\end{tabular}

\subsection{The Star Rating Interval of Ease-of-Use}

On the basis of the ease-of-use rating procedure proposed above, firstly getting the rating score of each indicator, and then obtaining four aspects rating scores and the comprehensive rating score. In order to make the ease-of-use rating results more apparently, this paper introduce the star rating method. According to the rating results of 18 tested car seats, with reference to five-star rating interval definition of NHTSA, this paper proposes the star rating interval for car seat ease-of-use rating procedure in China, as shown in Table 4.

Table 4 The Intervals of Star Rating Method

\begin{tabular}{|c|c|}
\hline$\star \star \star \star \star$ & $\mathrm{S} \geq 2.75$ \\
\hline$\star \star \star \star$ & $2.45 \leq \mathrm{S}<2.75$ \\
\hline$\star \star \star$ & $2.15 \leq \mathrm{S}<2.45$ \\
$\star \star \star$ & $1.85 \leq \mathrm{S}<2.15$ \\
\hline$\star$ & $\mathrm{S}<1.85$ \\
\hline
\end{tabular}

\section{Summary}

Firstly, this paper systematically and statistically analyzed the injury of children occupants in traffic accidents, the use rate of car seat and the misuse of car seat in China, and realized that the traffic injury is still a major cause to the children's injury and fatality, the rate of car seat usability is still very low in China. Then, this paper analyzed the children's injury by car seat misuse tests, and proposes the study method and rating framework about the Ease-of-Use Rating of car seat based on the different safety factors which are related to different misuse circumstances. Moreover, through the future analysis and verification, such as ease-of-use tests, misuse tests and hierarchical analysis, the China Car Seat Ease-of-Use Rating has been proposed in this paper.

\section{Acknowledgements}

We appreciate National Fund for Fundamental Research (Project ID:282015Y-4005). We also thank all the people who have contributed to this paper.

\section{References}

[1] Peden M., Oyegbite K., Ozanne-Smith J., et al. World Report on Child Injury Prevention. World Health Organization. 2008, 6-51

[2] European Road Safety Observatory. Traffic Safety Basic Facts 2008 Children(Age $<16) .2008$

[3] Zhang Jinhuan, Xu Shucai, Yang Xin, et al. Child Occupant Injury and Protection in Motor Vehicle Crashes. Beijing: Tsinghua University Press, 2015

[4] Javouhey E, Guerin A C, Gadegbeku B, et al. Are restrained children under 15 years of age in cars as effectively protected as adults? [J]. Archives of Disease in Childhood, 2006, 91(4): 304-308. [5] National Highway Traffic Safety Administration. Traffic Safety Facts[S/OL]. Available at 
http://www.nhtsa.dot.gov/Accessed May 1, 2008.

[6] SHANG Ting, TANG Boming, LIU Tangzhi. Status Quo of Child Safety Seat and Countermeasures in China[J]. Journal of Transport Information and Safety. 2010.28(5):69-72.

[7] Information on http://www.jt.sh.cn/jtw/flfg/n21/n341/u1ai52561.html .

[8]Information on http://www.hzrd.gov.cn/wxzl/flfg/hzsfg/yxfg/201604/t20160421_643332.html .

[9] Information on http://www.lcglj.com/zwgk/flfg/2015-01-19/172.html .

[10] Zhang Xiong. Research on Ease of Use Rating System for Vehicle Child Restraint System[D]. Tsinghua University, 2014.

[11] Liu Chen. Study on influencing factors on traffic injury severity based on the NAIS[D]. Tsinghua University, 2015.

[12] Decina L E, Lococo K H. Misuse of child restraints[R]. SAE Tech Paper, 2004. USDOT/NHTSA No. DOT HS 809671.

[13] Snowdon A W, Hussein A, Ahmed E. Canadian national survey on child restraint use 2010[R/OL].[2010-12-07]

[14] Koppel S. Child restraint system misuse and/or inappropriate use in Austratia [J]. Traffic Injury Prevention, 2009, 10:302-307.

[15] German Insurance Association. Misuse of child restraint systems: A 2008 observation study in Germany[R/OL]. [2009-01-01].

[16] GB 27887-2011: Restraint devices of Child Occupants of power-driven vehicles[S]. Beijing: General Administration Quality Supervision, Inspection and Quarantine of the People's Republic of China, 2011

[17] Zhang Jinhuan, Zhang Xiong, Xiao Lingyun, etc. Experimental studies on safety when child restraint system (CRS) misused [J]. Journal of Automotive Safety and Energy, 2014, 5(1):30-37. 